\title{
Ductography: The Diagnostic Procedure of Choice in Patients with Abnormal Nipple Discharge
}

A 38-year-old lady presented to the Ibn Sina Breast Care Centre, Dhaka with the complaints of bloody discharge through the left breast nipple. On examination, there was spontaneous bloody discharge from left breast nipple through a single duct. There was no mass on palpation. She was then referred for ultrasonography and ductography of the left breast. USG showed multiple cysts, however no intracystic solid portion could be noted. Ductography revealed dilated duct with contrast agent filling defects approximately $2.9 \mathrm{~cm}$ from the nipple and sudden cut-off of the contrast column about $3.7 \mathrm{~cm}$ from the nipple. Findings are consistent with intraductal papilloma with duct ectasia.

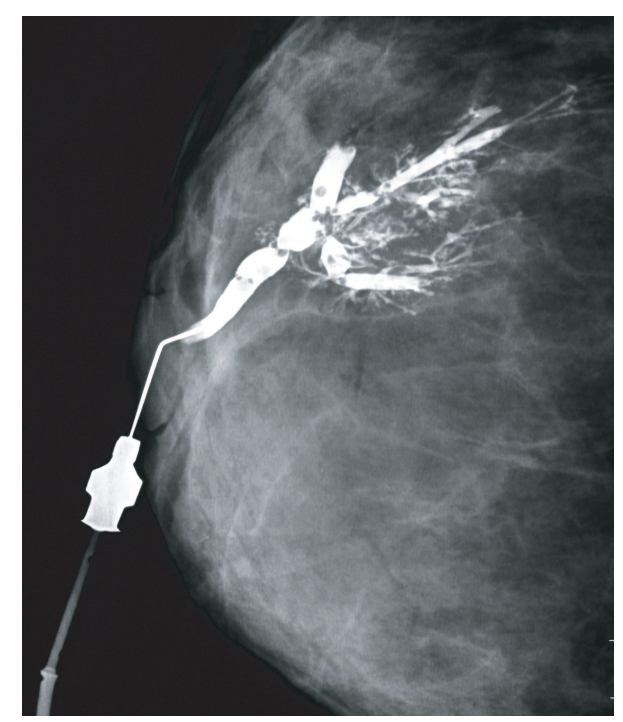

Fig 1. Galactography of left breast

Abnormal nipple discharge is associated with an underlying malignancy in $1.2 \%$ to $15 \%$ of patients. ${ }^{1}$ Abnormal discharge is defined as nonlactational, persistent, spontaneous, and unilateral. ${ }^{2}$ Bloody or hemoccult-positive discharge is more likely to be associated with cancer (5\% to $28 \%)$ and should prompt further evaluation. ${ }^{3}$ However, clear or watery discharge has been associated with breast cancer in up to $7 \%$ of cases. ${ }^{1}$ Mammography is advocated as part of the routine evaluation of women with breast complaints. Mammography is associated with a $9.5 \%$ false-negative rate and a $1.6 \%$ false-positive rate in detecting breast cancer in patients with nipple discharge. ${ }^{4}$ Ductography is an increasingly available method of examination and is relatively easy to perform with few complications. Ductography has been shown to be accurate in providing the location and depth of ductal abnormalities when a single duct is identified as the source. ${ }^{1}$ Data regarding the location of the lesion greatly facilitate biopsy, especially with deep lesions. Ductography has also been shown to improve the diagnostic yield of surgical biopsy from $67 \%$ in nonstudied patients to $100 \%$ in patients receiving a ductogram. ${ }^{5}$

\author{
Sharmin Akhtar Rupa \\ Associate Professor \\ Department of Radiology \& Imaging \\ Enam Medical College \& Hospital, Savar, Dhaka \\ Email: dr.sharminakhtarrupa@yahoo.com
}

\author{
Mahbooba Ishrat \\ Medical Officer \\ Ibn Sina Breast Care Centre, Dhaka
}

\section{Sonia Shahid}

Medical Officer

Ibn Sina Breast Care Centre, Dhaka

\section{References}

1. Tabar L, Dean PB, Pentek Z. Galactography: the diagnostic procedure of choice for nipple discharge. Radiology 1983; 149: 31-38.

2. Fiorica JV. Breast disease. Curr Opin Obstet Gynecol 1992; 4: 897-903.

3. Chaudary MA, Millis RR, Davies GC, Hayward JL. The diagnostic value of testing for occult blood. Ann Surg 1982; 196: 651-655.

4. Fiorica JV. Nipple discharge. Obstet Gynecol Clin North Am 1994; 21: 453-460.

5. Van Zee KJ, Ortega Perez G, Minnard E, Cohen MA. Preoperative galactography increases the diagnostic yield of major duct excision for nipple discharge. Cancer 1998; 82: $1874-1880$. 